\title{
Review
}

Acta Cytologica 2014;58:533-542

DOI: $10.1159 / 000362805$
Received: April 7, 2014

Accepted after revision: April 8, 2014 Published online: August 9, 2014

\section{Liquid-Based Cytology in Fine-Needle Aspiration of Breast Lesions: A Review}

\author{
Rene Gerhard Fernando C. Schmitt \\ Department of Laboratory Medicine and Pathobiology, Faculty of Medicine, University of \\ Toronto, and Department of Pathology, University Health Network, Toronto, Ont., Canada
}

\section{Key Words}

Liquid-based cytology · Breast · Fine-needle aspiration

\begin{abstract}
Objective: Fine-needle aspiration (FNA) is a safe and costeffective technique for the diagnosis of breast lesions, especially when correlated with clinical and imaging studies. However, the success of breast FNA is highly dependent on the adequate preparation of cytological conventional smears (CS). The liquid-based cytology (LBC) technique consists of an automated method for preparing thin-layer cytological samples from cell suspensions collected in alcoholbased preservative. LBC is designed to improve CS by avoiding limiting factors such as obscuring material, air-drying and smearing artifacts. Study Design: We performed a review of the published literature about LBC applied to breast FNA. Results: LBC preparations of breast aspirates demonstrated better cellular preservation, less cell overlapping and elimination of blood and excessive inflammation compared to CS. Conversely, alterations in architecture and cell morphology as well as loss of myoepithelial cells and stromal elements have been described in LBC specimens, requiring training before applying this technique for diagnosis. Studies have shown a similar accuracy between LBC and $\mathrm{CS}$ for the diagnosis of breast lesions. $\mathrm{LBC}$ also permits the
\end{abstract}

use of residual material for ancillary tests, which is an important advantage compared to CS. Conclusions: LBC can be safely applied to breast FNA, showing a similar diagnostic accuracy to CS.

(c) 2014 S. Karger AG, Basel

\section{Introduction}

Although largely replaced by core needle biopsy, fineneedle aspiration (FNA) still has a role in the assessment of breast lesions, especially when integrated in a multidisciplinary setting comprising cytopathologists, radiologists and clinicians $[1,2]$. FNA is a safe, rapid and lowcost technique with high diagnostic accuracy for breast lesions when the cytological findings are correlated with clinical and radiological studies (the 'triple assessment') $[1,3]$. Similar diagnostic results are found between core needle biopsy and FNA of palpable breast nodules, but important limitations of FNA have been recognized, including the inability to discriminate in situ from invasive carcinomas, a nondefinitive diagnosis for borderline lesions (atypical ductal hyperplasia, sclerosing and papillary lesions, low-grade carcinomas, and lobular lesions) and a higher rate of unsatisfactory results in comparison to core needle biopsy $[4,5]$.

\section{KARGER}

E-Mail karger@karger.com

www.karger.com/acy (c) 2014 S. Karger AG, Basel

$0001-5547 / 14 / 0586-0533 \$ 39.50 / 0$
Correspondence to: Prof. Fernando Schmitt

Department of Laboratory Medicine and Pathobiology, Faculty of Medicine, University of Toronto, University Health Network, Toronto General Hospital 200 Elizabeth Street, 11E-215B, Toronto, ON M5G 2C4 (Canada)

E-Mail fernando.schmitt@uhn.ca 
Currently, breast FNA has a significant role in the evaluation of clinical and radiological benign nodules, symptomatic breast lumps, local recurrences or metastasis of breast malignancies, assessment of lymph node status, and diagnosis of advanced breast tumors in patients with inoperable conditions [4]. However, the success of breast FNA is highly dependent on the skills of the individual performing the procedure and the adequate preparation of the cytological smears, as well as the experience of the cytopathologist in interpreting the slides [1-3]. In this regard, when there are no trained practitioners to adequately collect and handle FNAs, the liquid fixation and the thin-layer slide technique may overcome problems related to ill-preserved and poorly prepared smears $[6,7]$.

The liquid-based cytology (LBC) technique consists of an automated method for preparing thin-layer cytological samples onto glass slides from cell suspensions collected in alcohol-based preservative. The ThinPrep ${ }^{\mathrm{TM}}$ (TP; Hologic, Marlborough, Mass., USA) and the SurePath $^{\mathrm{TM}}$ (SP; BD TriPath, Burlington, N.C., USA) systems are the most common methods used in LBC for both gynecological (cervicovaginal samples) and nongynecological material, including FNA specimens. These methods are designed to improve the conventional cytological preparations by avoiding limiting factors such as obscuring material, air-dried artifacts and irregular thickness of the smears [7].

LBC has been largely employed in the evaluation of cervicovaginal specimens, replacing, in many countries, the Papanicolaou screening based on conventional smears (CS). Alleged advantages of LBC for gynecological cytology include improvement in specimen quality and adequacy, lower unsatisfactory rates, increased detection of precursor lesions, and the usage of residual samples for ancillary tests $[8,9]$. In general, studies that reported the use of LBC for body fluids and FNA specimens, including breast aspirates, found better cellular preservation, less cell overlapping and elimination of obscuring elements (blood, inflammatory cells and cellular debris) in comparison to CS [7, 10-12].

On the other hand, alterations in architecture and cellular morphology as well as loss of informative background (stromal cells and extracellular material) have been described in FNA specimens prepared by LBC [7, 13-16]. Because of that, some authors have advocated that prior training in LBC is necessary to avoid potential pitfalls and diagnostic errors $[7,15,16]$. In this review, we describe the cytomorphological findings, the diagnostic performance and the role of ancillary tests in LBC of breast aspirates.

\section{General Cytomorphological Characteristics}

The cytomorphological findings of breast FNA were analyzed by several studies that compared specimens processed by thin-layer technology - mainly TP and SP - to those prepared as CS.

\section{Cellularity}

Regarding nongynecological samples that included body fluids as well as FNA specimens, the cellularity in LBC was described as equal [11], slightly inferior [10] or slightly superior [7] to that in CS. Greater epithelial cellularity was reported in two studies that addressed only breast aspirates $[12,14]$. A more recent study showed a similar cell population between SP and CS for both benign and malignant breast lesions [16]. Nevertheless, we have to take into account that the quality and cellularity of the samples largely depends on the number of FNA passes and the skills of the practitioner performing the procedure.

\section{Architectural Features}

Studies have shown that cellular aggregates are fragmented, shortened and less distinct in LBC preparations, resulting in smaller clusters and cellular dissociation [7, $10,17]$. In another study, even though cellular cohesiveness was not altered, a three-dimensional arrangement was found to be more pronounced in both benign and malignant breast lesions [16]. The presence of small clusters, loss of cohesion and three-dimensional configuration may lead to an erroneous diagnosis of malignancy.

\section{Cell Changes}

Nongynecological specimens processed by LBC showed significant cellular alterations in comparison to those prepared as CS. Because the cells are fixed in a liquid medium they tend to be rounded and smaller than the flattened cells of a CS $[6,7]$. Some studies showed poor cellular preservation [18] and decreased nuclear features [13] on TP and swollen nuclei on SP [17]. However, the majority of the studies showed better-preserved cells with enhanced nuclear detail, including a well-defined, usually more pronounced, nucleoli $[7,10,11,14,16]$. Darkerstained nuclei (hyperchromasia) were found in both benign and malignant breast specimens prepared as SP slides [16]. According to Feoli et al. [15], nuclear changes can be very subtle in cases of tubular carcinoma, papillary carcinoma and low-grade invasive ductal carcinomas, resulting in a high rate of false-negative diagnoses before LBC training. The cytoplasm can be dense or overstained [17], but the cells located in the periphery of cell aggre- 
gates may show frayed cytoplasm [7]. Myoepithelial cells (bipolar cells) are usually less apparent or decreased in number in breast aspirates prepared by LBC. Moreover, some myoepithelial cells may have an intact cytoplasm resembling fibroblasts [7] or epithelial cells [15].

\section{Background Elements}

The studies are consensual regarding the presence of a clean background in nongynecological specimens prepared by LBC as a result of the elimination of obscuring elements such as blood, excessive inflammation and cellular debris [7, 10-12, 16-18]. One study described that the presence of leukocytes can help in the diagnosis of mastitis [12], but some studies stated that it is difficult to determine whether the inflammatory cells present in LBC specimens are secondary to lysed blood or a true inflammatory process $[7,10]$. On the other hand, an informative' background may also be eliminated. This includes a decrease or loss of extracellular material such as mucus $[7,10,12]$ and stromal fragments $[7,13,16]$. Adipocytes can be destroyed, rendering it difficult to make a single diagnosis in cases of lipoma or fat necrosis [12].

\section{Quality of LBC Preparations}

Despite some claims to the contrary [18], recent studies have shown that the quality of LBC preparations are similar or slightly superior in comparison to CS. Obscuring elements and air-drying and spreading artifacts are significantly reduced in TP [15] and SP [16] preparations. Although the quality of FNA specimens depends largely on the skills of the practitioner obtaining the samples, the problem of poor smear preparations may be solved by collecting the material in the appropriate vials provided by the different LBC systems.

\section{'Selected' Breast Lesions}

Some kinds of benign and malignant breast lesions prepared by the LBC technique have different cytomorphological features compared to those on CS preparations. These include fibroepithelial lesions, such as fibroadenoma and papillary lesions, and certain types of breast carcinomas. Recognizing these differences (and potential pitfalls) may help in making a correct diagnosis.

\section{Fibroadenoma}

CS preparations of fibroadenomas usually show cellular specimens consisting of large and cohesive branching sheets of ductal epithelial cells, numerous myoepithelial cells (bipolar cells) and fragments of fibromyxoid stroma [19] (fig. 1). Similar features such as the presence of ductal cells in staghorn clusters, isolated myoepithelial cells and stromal fragments have been described in cases of fibroadenomas processed by TP $[11,20]$. However, different architectural and cell changes have been reported by several studies. In fact, the diagnosis of fibroadenoma seems to be most problematic on LBC preparations, with some studies showing a low diagnostic rate compared to CS [13] and false-positive diagnoses while overclassifying fibroadenomas as atypical or suspicious [14]. Small cell aggregates (in contrast to large branching sheets) [7, 10], a decrease in numbers of myoepithelial cells $[7,10,13]$ and paucity or loss of stromal fragments [13] were found in LBC specimens of fibroadenomas. More importantly, enhanced cellular dyshesion and prominent nucleoli were potential diagnostic pitfalls in these specimens [7, $15,16]$. Indeed, one study showed that all benign breast lesions that were misdiagnosed as 'atypical/indeterminate' corresponded to fibroadenomas in which prominent nucleoli and a three-dimensional arrangement were present in SP but not in CS preparations [16]. Nevertheless, cellular dissociation and nuclear pleomorphism are not specific features of LBC preparations as these features may be present in almost half of the fibroadenomas seen on CS and may also result in diagnostic errors [19].

\section{Papillary Lesions}

One study proposed simplistic algorithms for the morphological distinction between fibroadenomas and papillary neoplasms on TP specimens. While staghorn clusters, fibromyxoid stroma and single cells consisting predominantly of myoepithelial cells are characteristic features of a fibroadenoma, the presence of papillary clusters and single columnar cells are findings highly suggestive of a papillary neoplasm [20] (fig. 2). In reality, this is not a simple issue because fibroadenomas (and also fibrocystic changes) can show a 'papillary pattern' on cytology. Another controversial issue is distinguishing an intraductal papilloma from a papillary carcinoma of the breast based only on cytomorphological findings. Because of that, some authors have suggested that the best approach for these lesions is excisional biopsy for a definitive diagnosis [5]. Despite the overlapping features seen on CS of aspirates from papillary lesions, papillary carcinomas tend to show slender and complex papillae, fibrovascular cores, an increased number of dissociated tall columnar cells, and variable nuclear atypia. In contrast, papillomas usually reveal broader branching fragments with rounded contours, fewer columnar cells, scarce-to-moderate 

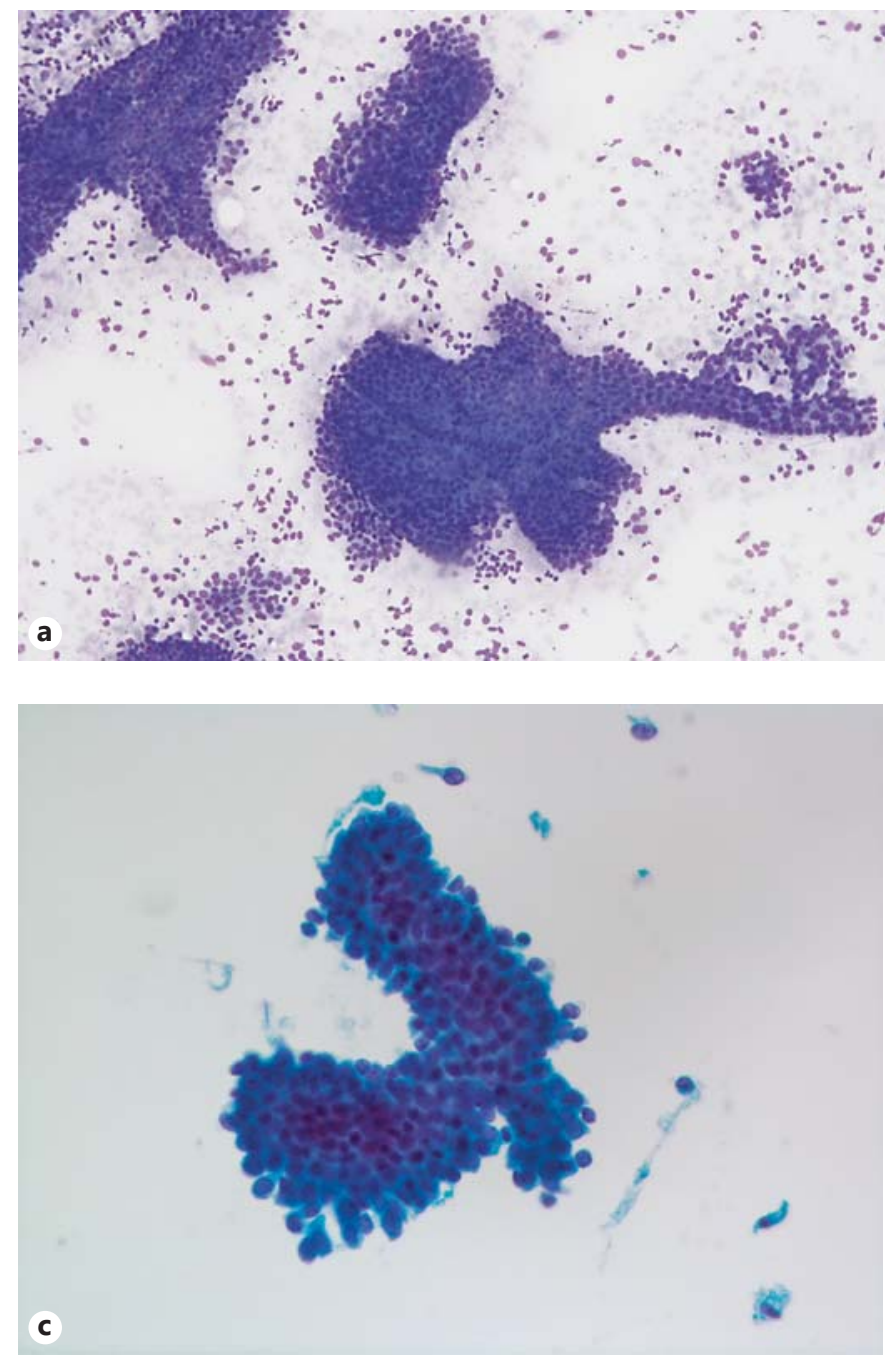

Fig. 1. Representative cytomorphological features from aspirates of fibroadenomas. a Cohesive cluster of ductal epithelial cells admixed with numerous myoepithelial cells ('bare nuclei') in the background. CS. Giemsa stain. $\times 100$. b An 'informative' background showing myoepithelial cells and a fragment of fibromyxoid and metachromatic stroma. CS. Giemsa stain. $\times 100$. c Cohesive

numbers of myoepithelial cells, and apocrine cells [21, $22]$. Unfortunately, there is no study that consistently addressed the cytomorphological features of breast papillary lesions on LBC preparations, which is an opportunity for further investigation.

\section{Breast Carcinomas}

The majority of breast carcinomas can be reliably diagnosed by FNA. Both types of cytological preparations (TP/SP and CS) have comparable performance for the detection of breast carcinomas $[12,14,16]$. Dey et al. [11]
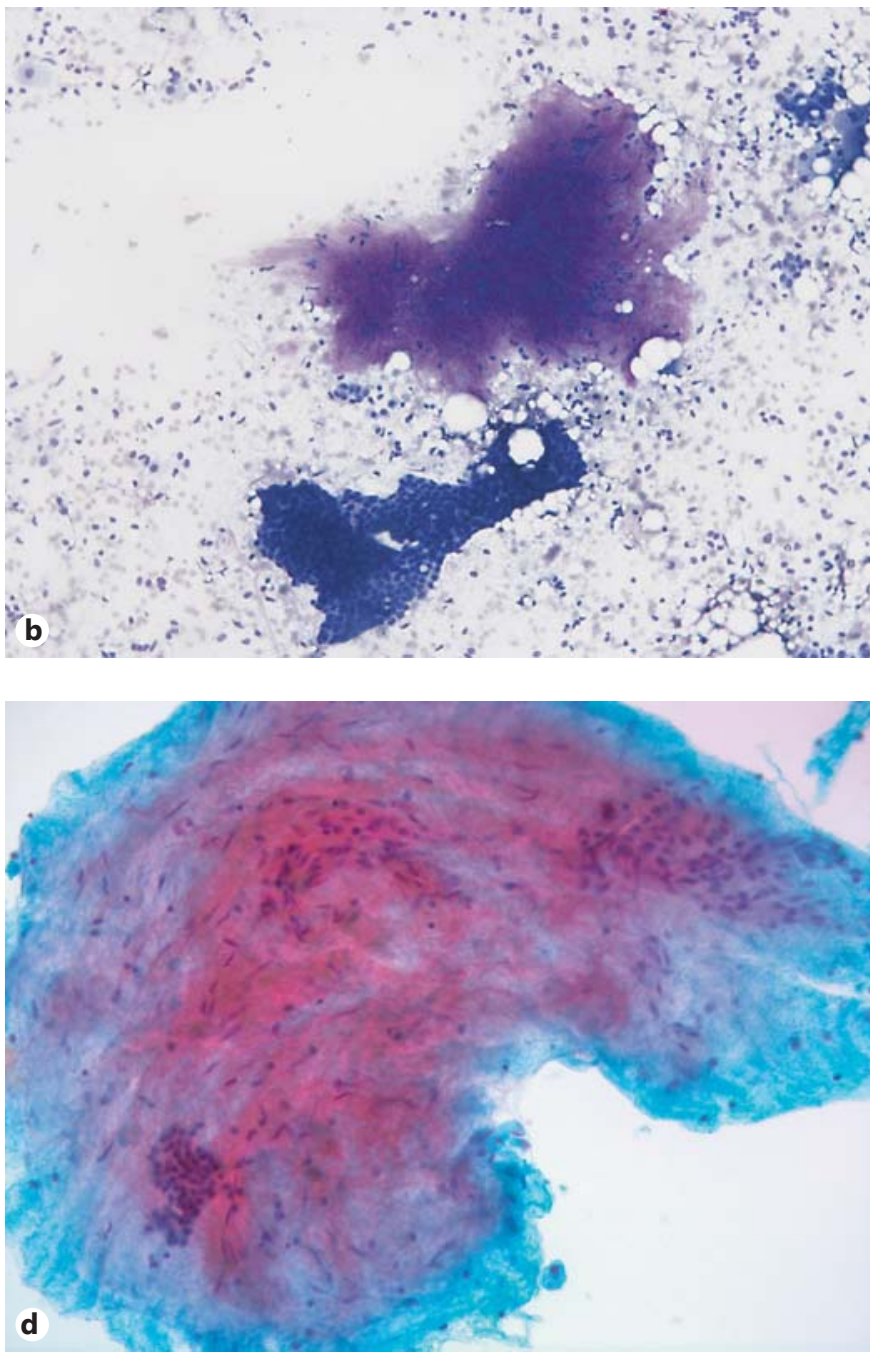

cluster of ductal epithelial cells with overlapping myoepithelial cells (small, dark-stained nuclei) in a clean background containing no 'bare nuclei'. TP. Papanicolaou stain. $\times 400$. $\mathbf{d}$ In this case, a fibromyxoid stroma with entrapped epithelial groups is identified, but with no myoepithelial cells in the background. TP. Papanicolaou stain. $\times 400$. stated that it was easier to diagnose invasive duct carcinomas on TP because of the clear background and the detailed nuclear features of the neoplastic cells. However, a clean background means an uninformative background because traditional diagnostic clues associated with malignancy, such as blood and necrotic material, are usually lost on LBC preparations [10, 11]. Ryu et al. [16] found remarkable differences of nuclear features in breast carcinomas processed by SP in comparison to CS, including more prominent nucleoli, hyperchromasia and less coarse chromatin. Regarding the architectural findings, some 

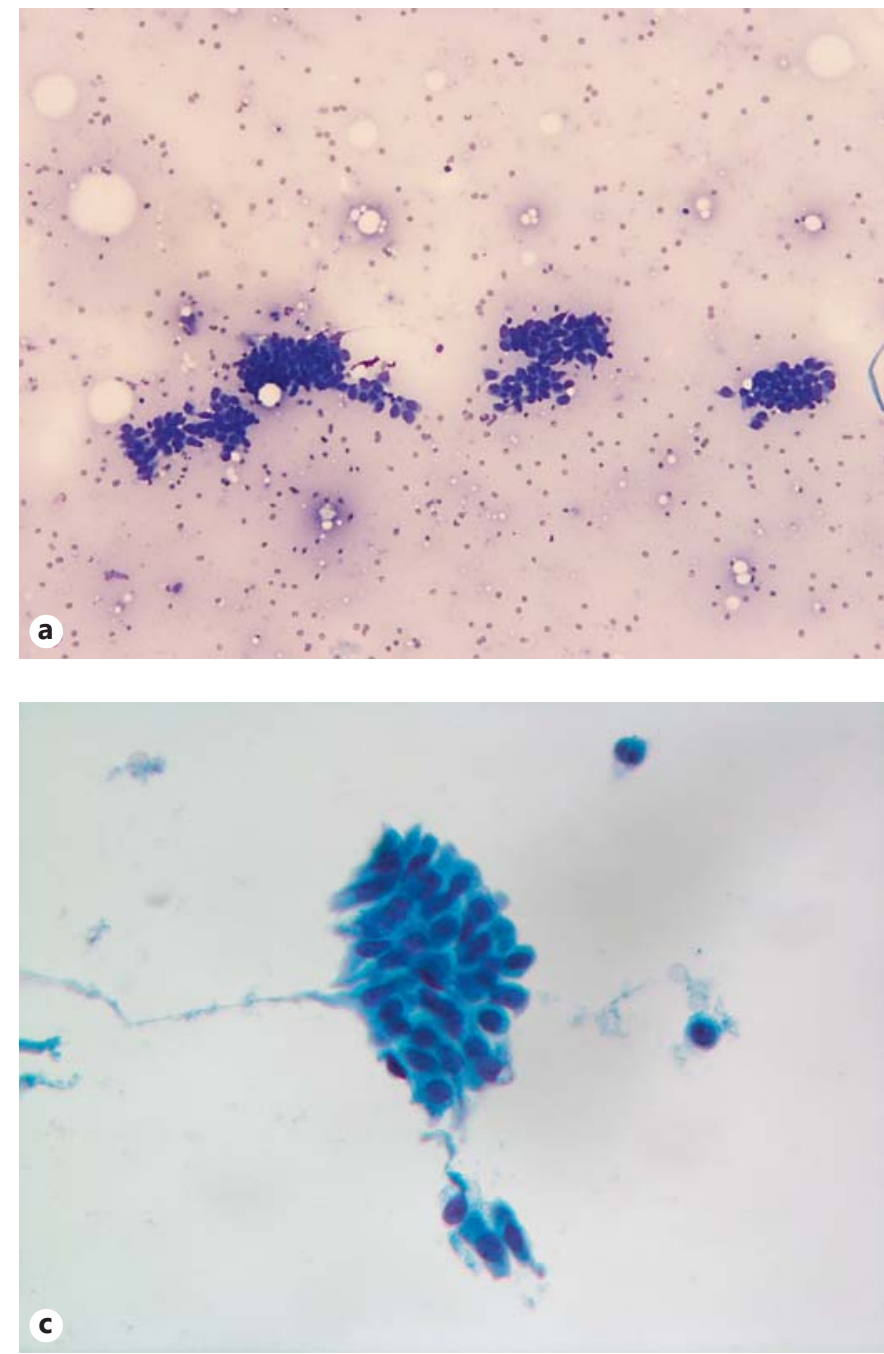

Fig. 2. Cytomorphology of papillary lesions of the breast. a Small groups of columnar epithelial cells are seen against a background containing proteinaceous material. CS. Giemsa stain. $\times 100$. b Columnar epithelial cells arranged in a complex cluster. CS. Giemsa stain. $\times 400$. c Columnar epithelial cells detached or arranged in

studies reported that large clusters of neoplastic cells are reduced to smaller aggregates $[7,11]$. Compared to CS, three-dimensional clusters are more frequently found in SP preparations [16], contrasting with the more common flattened-cell aggregates present on TP slides [7] (fig. 3).

Mucinous carcinomas and low-grade carcinomas (invasive and in situ ductal carcinomas, tubular and lobular carcinomas) of the breast are reported to be difficult to diagnose using LBC methods [7]. The diagnosis of a mucinous carcinoma by cytology depends largely on the presence of mucus in the background, which can be re-
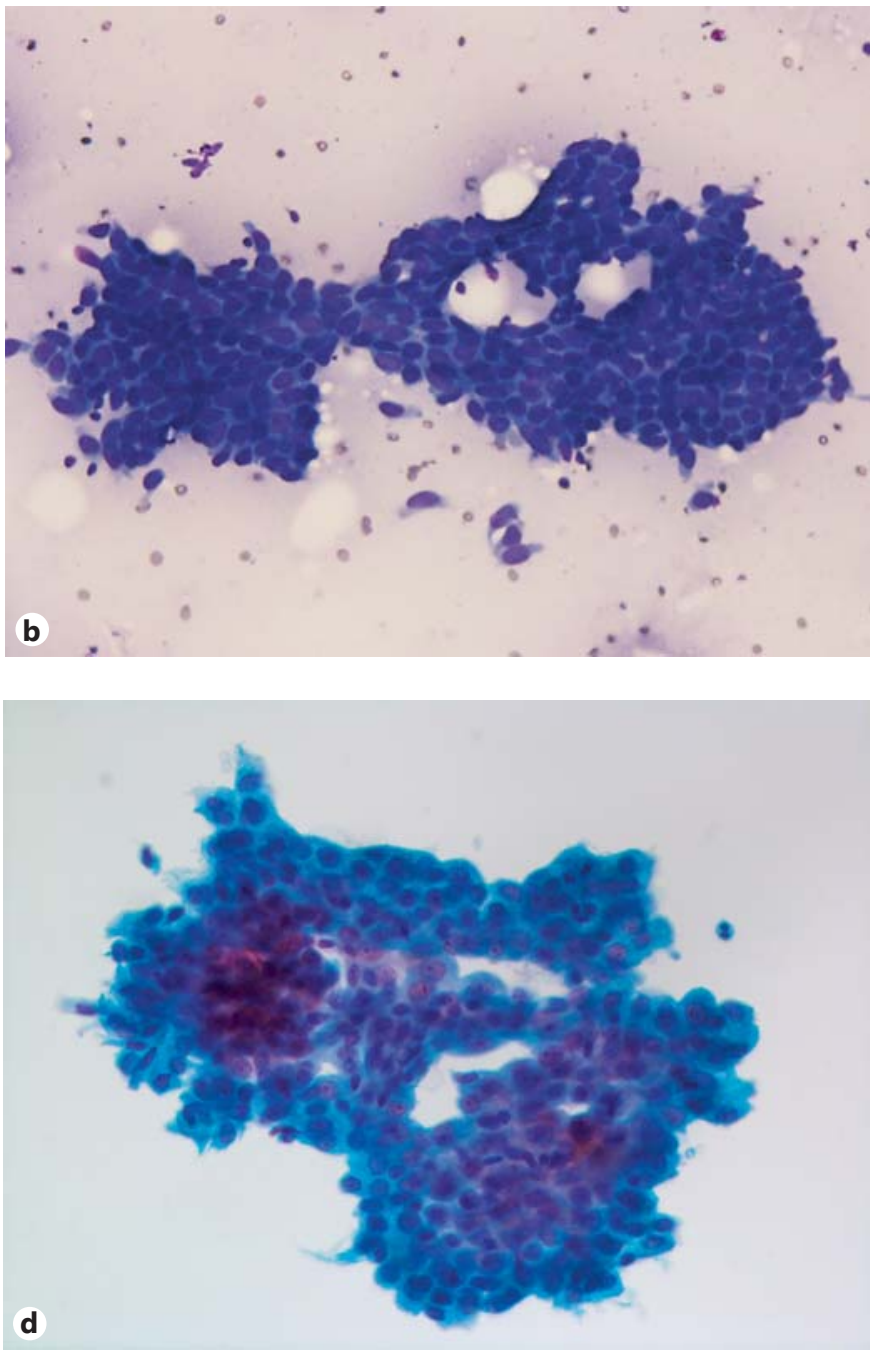

small groups in a clear background. TP. Papanicolaou stain. $\times 400$. d Cuboidal to columnar epithelial cells in a complex ramified cluster, showing round regular nuclei with fine chromatin and conspicuous nucleoli. TP. Papanicolaou stain. $\times 400$. duced or lost in LBC preparations. In one study, this diagnosis was missed because this material was not present on SP slides [12]. In contrast, analyzing SP preparations obtained from surgical specimens of breast cancer, Komatsu et al. [17] detected the presence of mucus in their single case of mucinous carcinoma. A study that analyzed the interlaboratory diagnostic reproducibility of mucinous carcinoma of the breast by cytology found that this diagnosis was statistically significantly better accomplished for Giemsa-stained CS specimens in comparison to either CS or TP Papanicolaou-stained material [23]. 

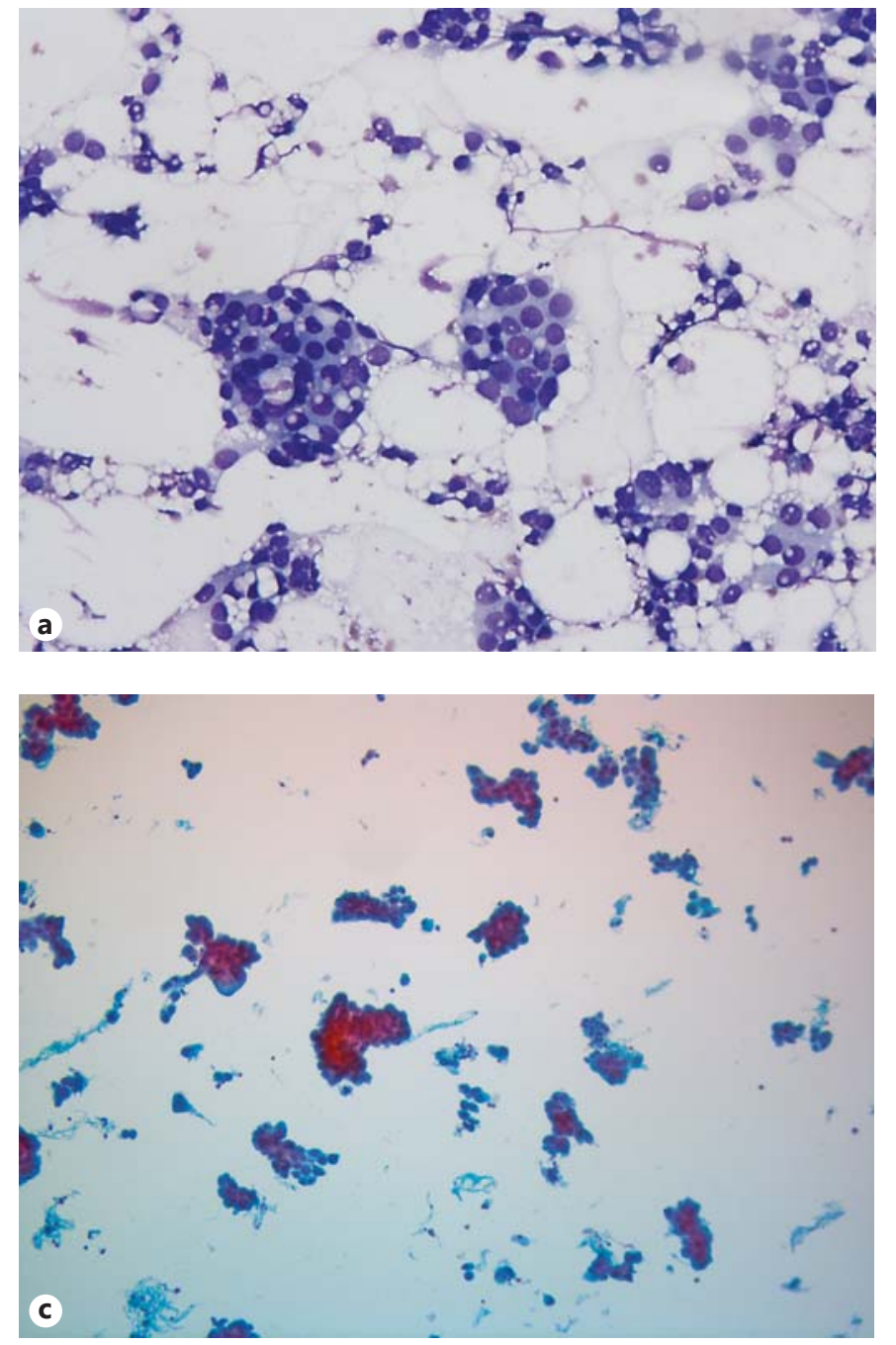

Fig. 3. Cytomorphological features of breast carcinomas sampled by FNA. a Single and small groups of malignant epithelial cells in a background of fat globules and adipose tissue. CS. Giemsa stain. $\times 200$. b Neoplastic cells show enlarged round nuclei and delicate cytoplasm. CS. Giemsa stain. $\times 400$. c Highly cellular specimen

The cytological diagnosis of low-grade breast carcinomas is difficult due to their mild nuclear atypia and small numbers of single abnormal cells [5]. Some cases of lowgrade ductal carcinoma in situ were reported as negative in one study [24]. According to the authors, these cases revealed cohesive clusters of ductal cells with small and monomorphic nuclei on TP slides. In the study of Ryu et al. [16], low-grade invasive or in situ ductal carcinomas that were cytologically diagnosed as negative or 'atypia/ indeterminate' were characterized by three-dimensional clusters with discreet nuclear features (fine chromatin and inconspicuous nucleoli) accompanied by few isolated
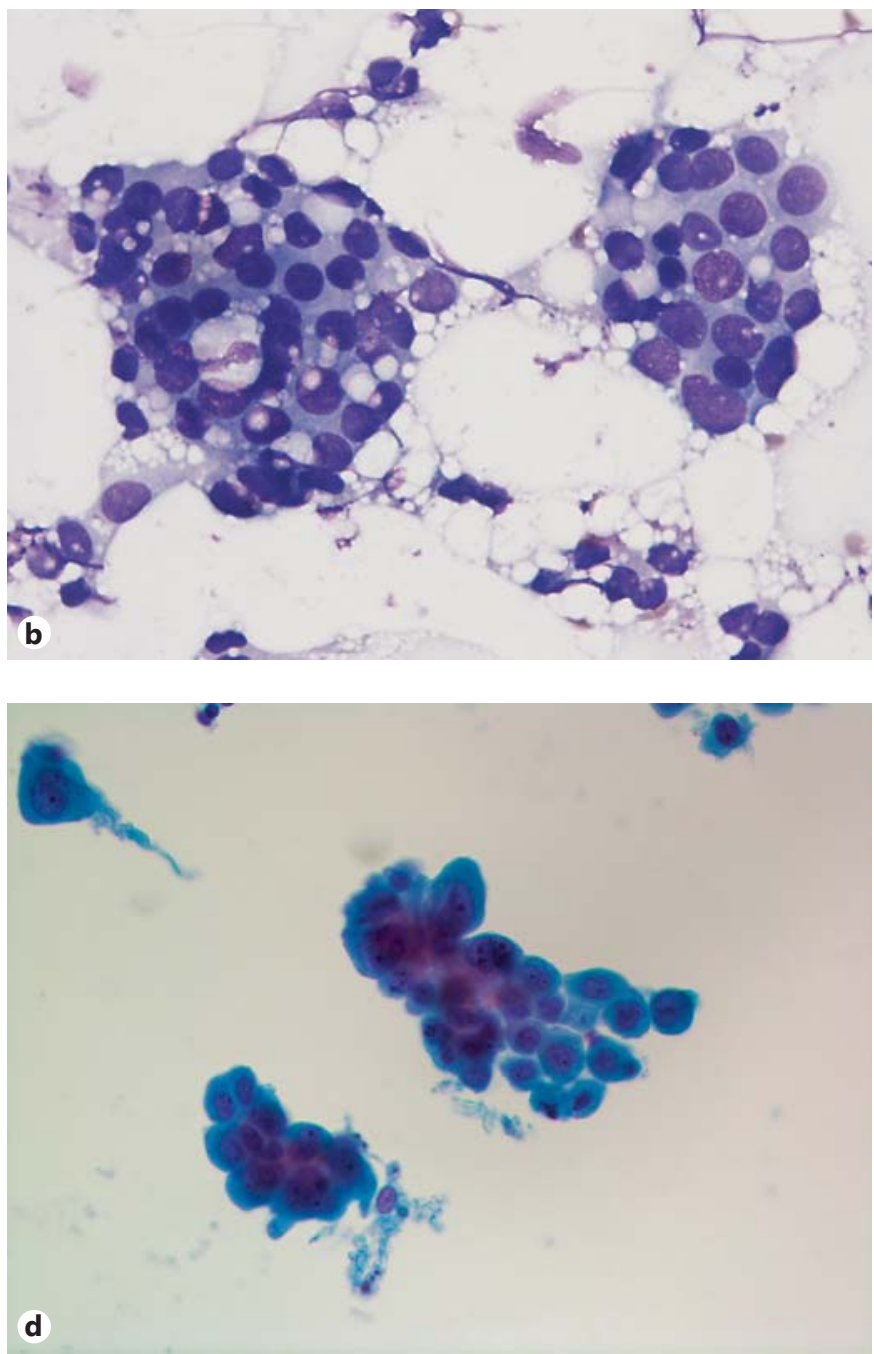

consisting of numerous clusters of malignant epithelial cells. TP. Papanicolaou stain. $\times 100$. d Neoplastic cells with preserved nuclear details characterized by enlarged nuclei, granular chromatin and prominent nucleoli. TP. Papanicolaou stain. $\times 400$.

single neoplastic cells on SP preparations. Furthermore, CS of the same lesions showed very similar features, except for a less fine chromatin and the presence of nuclear pleomorphism.

FNA diagnosis of tubular and lobular carcinomas may be challenging and a source of false-negative results [5]. Feoli et al. [15] clarified 2 cases of tubular carcinoma that were initially misdiagnosed as benign. Reviewing the TP slides, the authors observed neoplastic cells with slight nuclear atypia arranged in tight clusters with rigid borders, minimal cell stratification and absence of myoepithelial cells. Two studies exemplified the cytological find- 
ings of lobular carcinoma on LBC preparations. Biscotti et al. [14] illustrated a TP sample of a lobular carcinoma showing dyshesive cells with eccentric nuclei and wellpreserved nuclear detail in a clean background. More recently, Crossley et al. [25] reported the case of a patient with a lobular carcinoma of the breast metastatic to the cervix. After treatment with chemotherapy for her breast tumor, a cervical sample was obtained and was prepared by the SP method, displaying cells with high nuclear-cytoplasmic ratio, hyperchromasia and intracytoplasmic lumina that were consistent with a diagnosis of metastatic lobular carcinoma.

\section{Diagnostic Performance}

Very similar diagnostic performances have been found for nongynecological cytology processed by LBC or CS. An earlier study showed that the diagnostic accuracy of cytological material of body fluids and FNA specimens prepared by TP was the same as those of CS [10]. Another study compared large series of breast aspirates prepared by CS (21,193 cases) or TP (7,903 cases) and found comparable rates of sensitivity (CS: $84.4 \%$, TP: $86.3 \%$ ), specificity (CS: $98.6 \%$, TP: $96.5 \%$ ) and positive (CS: $96.5 \%$, TP: $95.0 \%$ ) and negative (CS: 91.1\%, TP: $88.0 \%)$ predictive values for both types of cytological preparations [26]. Biscotti et al. [14] matched CS and TP preparations obtained by aspirates from 75 surgically resected breast lesions (including 32 carcinomas) and observed $100 \%$ sensitivity for the detection of malignancy for both methods. However, in their study, the TP technique was inferior in definitively classifying benign breast lesions, showing a lower specificity rate (74\%) than the CS method (93\%). A higher specificity rate was detected by Kontzoglou et al. [27]. Investigating the role of TP technique in 352 cases of benign and malignant breast aspirates, the authors observed few numbers of false-negative and false-positive cases, resulting in a sensitivity of $97.7 \%$, specificity of $98 \%$ and overall accuracy of $97.9 \%$. The impact of LBC training in diagnostic accuracy was verified in a study comprising 190 cases of breast aspirates using TP slides [15]. The authors demonstrated a significant improvement in sensitivity (from 86 to $94 \%$ ) and a lower false-negative rate (from 12 to $4 \%$ ) after LBC training. The diagnostic performance of SP in 137 cases of breast FNA was investigated in a single study [16]. The results were comparable, but slightly lower specificity, positive predictive value and diagnostic accuracy rates were found for the SP technique in comparison to CS.

Liquid-Based Cytology in Breast Aspirates

\section{Ancillary Techniques}

Currently, the investigation of specific cell receptors such as hormonal receptors and the human epidermal growth factor receptor-2 (HER-2) is mandatory in all cases of invasive breast carcinoma because they are therapeutic targets in these types of tumors.

\section{Hormonal Receptors}

Nuclear hormonal receptors are frequently expressed in breast cancer: estrogen receptor (ER) and progesterone receptor (PR) are detected by immunohistochemistry in approximately $80 \%$ and $60-70 \%$ of invasive carcinomas, respectively. Positivity for hormonal receptors is associated with response to hormonal therapies and a better outcome [28]. Determination of hormonal receptors by immunohistochemistry can be performed in cytological specimens, including CS (air-dried or ethanol-fixed) and cell blocks, and the results are comparable to those performed on tissue specimens that are formalin-fixed and paraffin-embedded (FFPE) $[29,30]$. Excellent results can also be achieved using the LBC method. Using TP slides from malignant breast aspirates, Leung and Bedard [31] reported an overall accuracy of 97 and $89 \%$ for the detection of ER and PR, respectively. In another study, stronger immunostaining was observed on TP slides in comparison to histological samples [17]. Although not statistically significant, a higher number of cases positive for ER and PR was detected on slides prepared by the TP technique in comparison to CS [32]. Microwave antigen retrieval pretreatment before immunostaining is usually advocated for TP slides [31, 32]. In fact, a recent multinational study demonstrated a great variability in the detection of ER and PR in breast FNA specimens because of the different types of cytological preparations and the diverse methods of fixation and immunostaining protocols used by the laboratory participants. The study concluded that the best results were obtained when antigen retrieval and cytospin or thin-layer preparations were used [33].

The preservation of ER and PR antigenicity over long periods is an important advantage of LBC over CS. Using a breast cell line positive for ER and PR (ZR-75-1), Tabbara et al. [34] demonstrated that immunostaining for both hormonal receptors was retained on TP slides stored at room temperature for up to 56 days. Moreover, newly prepared slides of the residual material stored for the same period showed similar immunostaining results to the slides previously stored at room temperature. Sauer et al. [32] observed that the expression of ER and PR was almost unchanged in TP slides stored at different tem- 
peratures $\left(-20^{\circ} \mathrm{C}\right.$ or $-74^{\circ} \mathrm{C}$ ) and storing times $(3$ or 6 months) in relation to specimens prepared at time 'zero' and at room temperature.

\section{HER-2 Status}

The evaluation of HER-2 status is performed by immunohistochemistry and in situ hybridization (ISH) techniques such as fluorescence ISH (FISH), chromogenic ISH (CISH) or silver ISH (SISH). Amplification of the HER-2 gene is detected in around $15 \%$ of patients with invasive breast cancer. Targeted therapies against the HER-2 protein are advocated for patients whose tumors are HER-2 positive (i.e. protein expression score of $3+$ by immunohistochemistry or gene amplification determined by ISH) [28]. Recommendations for the assessment of HER-2 status in breast cancer were established by the American Society of Clinical Oncology (ASCO) and the College of American Pathologists (CAP) on FFPE tissue material obtained by core needle biopsies or excisional specimens [35]. In spite of the ASCO/CAP guidelines, several studies evaluated the HER-2 immunohistochemical status in cytological specimens of primary, recurrent and metastatic breast carcinomas [36]. However, the results were variable and controversial among diverse studies. Poor-to-moderate agreement between breast aspirates processed by different methods (ethanol-fixed, TP, formalin-fixed specimens) and FFPE tissue specimens tested for HER-2 were observed [37, 38]. Using two different antibodies anti-HER-2, Bèdard et al. [39] demonstrated a lower positive predictive value and lower specificity on TP slides in comparison to conventional histological material. The authors speculated that the methanol-based fixative of TP could be responsible for an increase in the sensitivity of antibodies, resulting in falsepositive results. In another study, immunostaining intensity for HER-2 was found to be stronger on TP slides in comparison to histology [17]. On the other hand, other studies observed excellent results using cell blocks prepared from cytological samples of breast tumors for the assessment of HER-2 status. Shabaik et al. [40], for example, demonstrated a $100 \%$ correlation for HER-2 expression between FFPE cell blocks and standard tissue sections of primary and metastatic breast carcinomas. In another study, either formalin-fixed or methanol-fixed cell blocks showed similar results for HER-2 expression [41].

Studies have demonstrated a good correlation between cytological and histological specimens of breast cancer for the determination of HER-2 status by ISH techniques. In the report of Beatty et al. [37], the HER-2 gene ampli- fication detected by FISH on cytological samples (ethanol-fixed CS and TP) showed consistent correlation with the HER-2 status determined by the HercepTest ${ }^{\mathrm{TM}}$ in FFPE tissue specimens. Using the CISH technique for HER-2 detection, Vocaturo et al. [42] verified that a high concordance rate was achieved between TP specimens and paired FFPE tissue sections from surgically resected breast carcinomas. In another study that investigated the role of dual SISH for the evaluation of HER-2 status in 47 invasive breast carcinomas, comparable results between cytological (TP) and histological material were achieved in $96 \%$ of the cases [43].

\section{Advantages and Disadvantages}

LBC preparations offer some advantages over CS. Slides prepared by either TP or SP techniques usually show a uniform, thin-layer distribution of cells, without significant cellular overlapping, and a clean background devoid of obscuring elements such as blood and inflammation $[7,15,16]$. LBC may overcome problems related to suboptimal smears such as air-drying and spreading artifacts, especially in the context where there are no welltrained practitioners to perform appropriate smears [7, 15]. Conversely, it is well established that both TP and SP techniques introduce cytomorphological features that are very dissimilar from those of CS, including architectural and cell changes, as previously described $[7,15,16,18]$. Recognizing these distinct cellular findings is the first step to avoiding interpretative errors. Because of that, training before screening and interpreting LBC preparations is highly recommended [7, 16]. Indeed, Feoli et al. [15] demonstrated a statistically significant improvement in the sensitivity and false-negative rates for the diagnosis of breast aspirates (using TP slides) after 6 months of training. However, one study showed that the artifacts present on TP slides of breast aspirates did not interfere with accurate diagnoses made by experienced cytopathologists who were comfortable with CS but unfamiliar with the TP preparations [24].

LBC permits the use of residual material for ancillary studies such as immunohistochemistry and ISH, which is an important advantage over CS. The remaining material can be kept in the appropriate containers and prepared slides can be stored for up to 6 months without loss of cell antigenicity [32]. Another aspect is the standardization of the method: multiple slides that are relatively homogeneous regarding the cell content can be prepared for immunohistochemical panels [34]. 
In comparison to CS, LBC can add costs to the laboratory. This aspect may be counterbalanced when one considers that the LBC method decreases the number of prepared slides [12,27]. Moreover, this technique confines the cellular material to small areas on the slides which reduces the time spent on cytological evaluation [12,27]. Therefore, saving the time of qualified personnel is an important aspect for reducing laboratory costs [10].

\section{Conclusion}

LBC can be safely used in the diagnosis of breast aspirates. Despite of the characteristic cytomorphological features that require appropriate training to avoid misinterpretation, LBC has similar accuracy to CS for the cyto- logical diagnosis of breast lesions. Furthermore, LBC has important advantages over CS. The method is easier for the collection of samples, having the advantage of overcoming issues regarding poor CS preparations. The time for evaluation of LBC slides is significantly reduced compared to CS. Finally, the possibility to provide appropriate ancillary tests - such as immunohistochemistry for hormonal receptors and HER-2 or ISH techniques for the assessment of the HER-2 gene - is an invaluable characteristic of the LBC method in the context of primary and metastatic breast cancer.

\section{Disclosure Statement}

No financial support was received for this study.

\section{References}

1 Kocjan G, Bourgain C, Fassina A, Hagmar B, Herbert A, Kapila K, Kardum-Skelin I, Kloboves-Prevodnik V, Krishnamurthy S, Koutselini H, Majak B, Olszewski W, Onal B, Pohar-Marinšek Z, Shabalova I, Smith J, Tani E, Viehl P, Wiener H, Schenck U, Schmitt F: The role of breast FNAC in diagnosis and clinical management: a survey of current practice. Cytopathology 2008;19:271-278.

2 Simsir A, Rapkiewicz A, Cangiarella J: Current utilization of breast FNA in a cytology practice. Diagn Cytopathol 2009;37:140-142.

-3 Rosa M, Mohammadi A, Masood S: The value of fine needle aspiration biopsy in the diagnosis and prognostic assessment of palpable breast lesions. Diagn Cytopathol 2012;40:2634.

- Nassar A: Core needle biopsy versus fine needle aspiration biopsy in breast - a historical perspective and opportunities in modern era. Diagn Cytopathol 2011;39:380-388.

5 Simsir A, Cangiarella J: Challenging breast lesions: pitfalls and limitations of fine-needle aspiration and the role of core biopsy in specific lesions. Diagn Cytopathol 2012;40:262272.

6 Kurtycz DFI, Hoerl HD: Thin-layer technology: tempered enthusiasm. Diagn Cytopathol 2000;23:1-5.

7 Michael CW, Hunter B: Interpretation of fine-needle aspirates processed by the Thin Prep ${ }^{\circledR}$ technique: cytologic artifacts and diagnostic pitfalls. Diagn Cytopathol 2000;23:613.

8 Cibas ES: Cervical and vaginal cytology; in Cibas ES,Ducatman BS (eds): Cytology: Diagnostic Principles and Clinical Correlates. Philadelphia, Saunders, 2009, pp 1-63.
>9 Hoda RS, Loukeris K, Abdul-Karim FW: Gynecological cytology on convention and liquid-based preparations: a comprehensive review of similarities and differences. Diagn Cytopathol 2013;41:257-278.

10 Leung CS, Chiu B, Bell V: Comparison of ThinPrep and conventional preparations: nongynecologic cytology evaluation. Diagn Cytopathol 1997;16:368-371.

11 Dey P, Luthra UK, George J, Zuhairy F, George SS, Haji BI: Comparison of ThinPrep and conventional preparations on fine needle aspiration cytology material. Acta Cytol 2000; 44:46-50.

12 Veneti S, Daskalopoulou D, Zervoudis S, Papasotiriou E, Ioannidou-Mouzaka L: Liquidbased cytology in breast fine needle aspiration. Comparison with the conventional smear. Acta Cytol 2003;47:188-192.

13 Perez-Reyes N, Mulford DK, Rutkowski MA, Logan-Young W, Dawson AE: Breast fineneedle aspiration: a comparison of thin-layer and conventional preparation. Am J Clin Pathol 1994;102:349-353.

$\checkmark 14$ Biscotti CV, Shorie JH, Gramlich TL, Easley KA: ThinPrep versus conventional smear cytologic preparations in analyzing fine-needle aspiration specimens from palpable breast masses. Diagn Cytopathol 1999;21:137-141.

15 Feoli F, Ameye L, Van Eeckhout P, Paesmans M, Marra V, Arisio R: Liquid-based cytology of the breast: pitfalls unrecognized before specific liquid-based cytology training - proposal for a modification of the diagnostic criteria. Acta Cytol 2013;57:369-376.

16 Ryu HS, Park IA, Park SY, Jung YY, Park SH, Shin HC: A pilot study evaluating liquidbased fine needle aspiration cytology of breast lesions: a cytomorphological comparison of SurePath ${ }^{\circledR}$ liquid-based preparations and conventional smears. Acta Cytol 2013;57: 391-399.

17 Komatsu K, Nakanishi Y, Seki T, Yoshino A, Fuchinoue F, Amano S, Komatsu A, Sugitani M, Nemoto N: Application of liquid-based preparation to fine needle aspiration cytology in breast cancer. Acta Cytol 2008;52:591-596.

18 Nasuti JF, Tam D, Gupta PK: Diagnostic value of liquid-based (ThinPrep) preparations in nongynecologic cases. Diagn Cytopathol 2001;24:137-141.

19 Kollur SM, El Hag IA: FNA of breast fibroadenoma: observer variability and review of cytomorphology with cytohistological correlation. Cytopathology 2006;17:239-244.

20 Ali AS, Yin D, Yao D, Vazquez M: Criteria for the diagnosis of fibroepithelial lesions of the breast with liquid-based cytology. Acta Cytol 2004;48:481-486.

21 Michael CW, Buschmann B: Can true papillary neoplasms of breast and their mimickers be accurately classified by cytology? Cancer Cytopathol 2002;96:92-100.

22 Tse GM, Ma TK, Lui PC, Ng W, Yu AM, Vong JS, Niu Y, Chaiwun B, Lam WW, Tan PH: Fine needle aspiration cytology of papillary lesions of the breast: how accurate is the diagnosis? J Clin Pathol 2008;61:945-949.

23 Laucirica R, Bentz JS, Khalbuss WE, Clayton AC, Souers RJ, Moriarty AT: Performance characteristics of mucinous (colloid) carcino$\mathrm{ma}$ of the breast in fine-needle aspirates: observations from the College of American $\mathrm{Pa}$ thologists Interlaboratory Comparison Program in Nongynecologic Cytopathology. Arch Pathol Lab Med 2011;135:1533-1538. 
24 Gornstein B, Jacobs T, Bédard Y, Biscotti C, Ducatman B, Layfield L, McKee G, Sneige N, Wang H: Interobserver agreement of a probabilistic approach to reporting breast fine-needle aspirations on ThinPrep ${ }^{\circledR}$. Diagn Cytopathol 2004;30:389-395.

25 Crossley B, Rogers S, Kurien G: Diagnosis of asymptomatic metastatic lobular carcinoma of breast on conventional and liquid-based cervical cytology samples from the same patient. Cytopathology 2014;25:209-210.

26 Bedard YC, Pollett AF: Breast fine-needle aspiration. A comparison of ThinPrep and conventional smears. Am J Clin Pathol 1999;111: 523-527.

-27 Kontzoglou K, Moulakakis KG, Konofaos P, Kyriazi M, Kyroudes A, Karakitsos P: The role of liquid-based cytology in the investigation of breast lesions using fine-needle aspiration: a cytohistopathological evaluation. J Surg Oncol 2005;89:75-78.

28 Allred C, Miller K, Viale G: Molecular testing for estrogen receptor, progesterone receptor, and HER; in Lakhani SR, Ellis IO, Schnitt SJ Tan PH, van de Vijver MJ (eds): WHO Classification of Tumors of the Breast. Lyon, IARC, 2012, pp 22-23.

29 Cano G, Milanezi F, Leitão D, Ricardo S, Brito MJ, Schmitt FC: Estimation of hormone receptor status in fine-needle aspirates and paraffin-embedded sections from breast cancer using the novel rabbit monoclonal antibodies SP1 and SP2. Diagn Cytopathol 2003;29:2072011.

-30 Skoog L, Tani E: Immunocytochemistry: an indispensable technique in routine cytology. Cytopathology 2011;22:212-229.

31 Leung SW, Bèdard YC: Estrogen and progesterone receptor contents in ThinPrep-processed fine-needle aspirates of breast. Am J Clin Pathol 1999;112:50-56.
2 Sauer T, Ebeltoft K, Pedersen MK, Kåresen R: Liquid-based material from fine needle aspirates from breast carcinomas offers the possibility of long-time storage without significant loss of immunoreactivity of estrogen and progesterone receptors. Cytojournal 2010;7: 24.

33 Marinšek ZP, Nolde N, Kardum-Skelin I, Nizzoli R, Onal B, Rezanko T, Tani E, Ostović KT, Viehl P, Schmitt F, Kocjan G: Multinational study of oestrogen and progesterone receptor immunocytochemistry on breast carcinoma fine needle aspirates. Cytopathology 2013;24:7-20.

-34 Tabbara SO, Sidawy MK, Frost AR, Brosky KR, Coles V, Hecht S, Radcliffe G, Sherman ME: The stability of estrogen and progesterone receptor expression on breast carcinoma cells stored as PreservCyt suspensions and as ThinPrep slides. Cancer Cytopathol 1998;84: 355-360.

35 Wolff AC, Hammond ME, Schwartz JN, Hagerty KL, Allred DC, Cote RJ, Dowsett M, Fitzgibbons PL, Hanna WM, Langer A, McShane LM, Paik S, Pegram MD, Perez EA, Press MF, Rhodes A, Sturgeon C, Taube SE, Tubbs R, Vance GH, van de Vijver M, Wheeler TM, Hayes DF; American Society of Clinical Oncology; College of American Pathologists: American Society of Clinical Oncology/ College of American Pathologists guideline recommendations for human epidermal growth factor receptor 2 testing in breast cancer. J Clin Oncol 2007;25:118-145.

36 Beca F, Schmitt F: Growing indication for FNA to study and analyze tumor heterogeneity at metastatic sites. Cancer Cytopathol 2014, Epub ahead of print.

37 Beatty BG, Bryant R, Wang W, Ashikaga T, Gibson PC, Leiman G, Weaver DL: HER-2/ neu detection in fine-needle aspirates of breast cancer: fluorescence in situ hybridization and immunocytochemical analysis. Am J Clin Pathol 2004;122:246-255.
38 Williams SL, Birdsong GG, Cohen C, Siddiqui MT: Immunohistochemical detection of estrogen and progesterone receptor and HER2 expression in breast carcinomas: comparison of cell block and tissue block preparations. Int J Clin Exp Pathol 2009;2:476-480.

- 39 Bèdard YC, Pollett A, Leung SW, O’Malley FP: Assessment of thin-layer breast aspirates for immunocytochemical evaluation of HER2 status. Acta Cytol 2003;47:979-984.

40 Shabaik A, Lin G, Peterson M, Hasteh F, Tipps A, Datnow B, Weidner N: Reliability of HER2/neu, estrogen receptor, and progesterone receptor testing by immunohistochemistry on cell block of FNA and serous effusions from patients with primary and metastatic breast carcinoma. Diagn Cytopathol 2011;39: 328-332.

41 Gorman BK, Kosarac O, Chakraborty, Schwartz MR, Mody DR: Comparison of breast carcinoma prognostic/predictive biomarkers on cell blocks obtained by various methods: Cellient, formalin and thrombin. Acta Cytol 2012;56:289-296.

42 Vocaturo A, Novelli F, Benevolo M, Piperno G, Marandino F, Cianciulli AM, Merola R, Donnorso RP, Sperduti I, Buglioni S, Mottolese M: Chromogenic in situ hybridization to detect HER-2/neu gene amplification in histological and ThinPrep-processed breast cancer fine-needle aspirates: a sensitive and practical method in the trastuzumab era. Oncologist 2006;11:878-886.

43 Beraki E, Sauer T: Determination of HER-2 status on FNAC material from breast carcinomas using in situ hybridization with dual chromogen visualization with silver enhancement (dual SISH). Cytojournal 2010;7:21. 